\title{
All in the family: evolutionary and functional relationships among death receptors
}

\author{
JT Bridgham ${ }^{1}$, JA Wilder ${ }^{2}$, H Hollocher ${ }^{1}$ and AL Johnson ${ }^{\star, 1}$ \\ ${ }^{1}$ Department of Biological Sciences and Walther Cancer Center, University of \\ Notre Dame, Notre Dame, IN 46556, USA \\ 2 Department of Ecology and Evolutionary Biology, Princeton University, \\ Princeton, NJ 08544, USA \\ * Corresponding author: AL Johnson, Department of Biological Sciences, PO \\ Box 369, The University of Notre Dame, Notre Dame, IN 46556, USA Tel: 574 \\ 631 9450; Fax: 574-631-7413; E-mail: Johnson.128@nd.edu
}

Received 21.5.02; revised 15.7.02; accepted 28.10.02

Edited by J Nunez

\begin{abstract}
Over the last decade, significant progress has been made towards identifying the signaling pathways within mammalian cells that lead to apoptosis mediated by death receptors. The simultaneous expression of more than one death receptor in many, if not all, cell types suggests that functional innovation has driven the divergence of these receptors and their cognate ligands. To better understand the physiological divergence of the death receptors, a phylogenetic analysis of vertebrate death receptors was conducted based upon aminoacid sequences encoding the death domain regions of currently known and newly identified members of the family. Evidence is presented to indicate an ancient radiation of death receptors that predates the emergence of vertebrates, as well as ongoing divergence of additional receptors both within several receptor lineages as well as modern taxonomic lineages. We speculate that divergence among death receptors has led to their functional specialization. For instance, some receptors appear to be primarily involved in mediating the immune response, while others play critical roles during development and tissue differentiation. The following represents an evolutionary approach towards an understanding of the complex relationship among death receptors and their proposed physiological functions in vertebrate species.
\end{abstract}

Cell Death and Differentiation (2003) 10, 19-25. doi:10.1038/ sj.cdd. 4401174

Keywords: death receptors; vertebrates; apoptosis; phylogeny

Abbreviations: EST, expressed sequence tag; TNF, tumor necrosis factor; TNFR, TNF receptor; $\mathrm{Dr}$, Danio rerio; Hs, Homo sapiens; Mm, Mus musculus; Gg, Gallus gallus; XI, Xenopus laevis; St, Silurana tropicalis; OI, Oryzias latipes

\section{Introduction}

In all vertebrate cells, there exist multiple and often redundant apoptotic pathways which can be activated in response to a plethora of internal and external cellular signals. Internal pathways leading to apoptotic cell death may be initiated by stimuli including ultraviolet irradiation, growth factor withdrawal and chemotherapeutic agents, most of which induce mitochondrial perturbations often mediated via proapoptotic Bcl-2 family members. Affected mitochondria subsequently release cytochrome $c$, which combines with Apaf-1 to form the apoptosome complex, and/or Smac/Diablo, which inactivates Inhibitor of Apoptosis Proteins such as XIAP. Both of these factors ultimately promote a cascade of caspase enzyme activation leading to cell death. ${ }^{1,2}$

Alternatively, extracellular factors, in particular those from the tumor necrosis factor (TNF) family of ligands, bind to cognate members of the death domain-containing subfamily (death receptors) from the larger tumor necrosis factor receptor superfamily (TNFRSF), which then indirectly initiate the caspase cascade. Intracelluar death domains of activated death receptors recruit and bind cytoplasmic adaptor proteins via homophilic interactions, while adaptor proteins (eg. TNF receptor-1-associated protein, TRADD, and Fas associated via death domain FADD), in turn, interact with initiator caspases (e.g. caspase 8) through a death effector domain (DED). The processing of caspase-8 subsequently activates downstream caspases directly as well as initiates the mitochondrial signaling pathway described above, thus amplifying the initial signal and assuring eventual cell death. ${ }^{3-5}$ Importantly, the localization of TNF receptor family members to lipid rafts allows for the formation of these signaling platforms critical for the induction of downstream pathways. Also of interest, the death domain of TNFRI has recently been shown to be required for the localization of this receptor to the lipid rafts. ${ }^{6}$

Notably, several death receptors also mediate downstream signaling unrelated to cell death. Specifically, death receptors employ TNF receptor-associated factors (TRAFs) as transducers of their signaling pathways, the activation of which may promote cell survival, proliferation, and/or differentiation. TRAF proteins are responsible for the TNFRSF activation of both nuclear factor kappa-B (NF- $\mathrm{B}$ ) and mitogen-activated protein (MAP) kinase-mediated pathways. ${ }^{7}$ Alternatively, Tolllike membrane receptors, which are critical to the innate immune system (e.g. Toll-like receptor-2), can activate apoptotic pathways via adaptor proteins and TRAF family members, yet such receptors do not contain cytoplasmic death domains. ${ }^{8,9}$ Although involved in activating signaling pathways in common with death receptors, the Toll-like receptors are not considered to be directly related to death receptors, and will not be discussed further herein. 
Common features of all death receptors include multiple cysteine-rich repeats within the extracellular ligand-binding domain, a type I (single pass) transmembrane domain, and a cytoplasmic death domain required for intracellular signaling. ${ }^{10}$ Accordingly, death receptors represent a unique family of proteins with this characteristic domain architecture that allows them to transfer external signals to the cell.

Given the variable nature of the cysteine-rich domains, and their probable coadaptation with specific ligands, ${ }^{11}$ we chose to focus upon the conserved and functionally important death domain region to examine the phylogeny of the vertebrate death receptors. ${ }^{12}$ The boundaries of functional death domains have previously been described using functional deletion and mutational analyses to determine residues and regions critical to their death-including capabilities. $^{13-17}$

\section{Insights from non-mammalian model systems to study death receptor-mediated apoptosis}

Apoptosis plays a critical role in the functional restructuring of many tissues during early development (for instance, neuronal and epidermal tissues). In adults, this process occurs most routinely in tissues that continue to actively differentiate such as those within the immune system, intestinal epithelium, testis, and ovary. For example, vertebrate females produce an excess of ovarian follicles during early ontogeny, the vast majority of which are subsequently lost via follicle atresia prior to reaching the preovulatory stage. ${ }^{18}$ Numerous studies have been devoted to understanding the precise regulation of atresia by both extra- and intra-follicular factors, and much of this work has focused upon interactions between the oocyte and the somatic granulosa layer. ${ }^{19}$

Our laboratory has taken a comparative approach to understanding this process by utilizing the chicken (Gallus gallus) ovary model system. Perhaps not surprisingly, results thus far demonstrate that there exists a striking conservation of intracellular survival and cell death-mediating pathways between mammalian and this avian species. ${ }^{20}$ Thus, attention has recently been directed towards identifying extracellular signals that can induce selected follicles to undergo follicle atresia in the hen ovary. Specifically, ongoing studies are in progress to identify chicken orthologs from the TNF family of death domain-containing receptors, and to monitor death receptor expression and activation within the granulosa cell layer throughout the development of hen ovarian follicles. Significantly, all five of the currently identified Gallus death receptors (tumor necrosis factor receptor-I [TNFRI], Fas, TVB, p75 neurotrophin receptor [p75NTR], and death receptor 6 [DR6]) are known to be expressed in granulosa cells (Figure 1). A functional role for such receptors during atresia is suggested by the fact that four of the five receptors (TNFRI, Fas, DR6, TVB) are expressed at higher levels in atretic follicles compared to morphologically and functionally normal follicles (DR6 ${ }^{21}$; Fas and TNFRI, ${ }^{22}$ TVB,${ }^{23}$ p75NTR, Johnson, unpublished).

In light of these observations, an obvious question arises as to why a single cell type should express so many

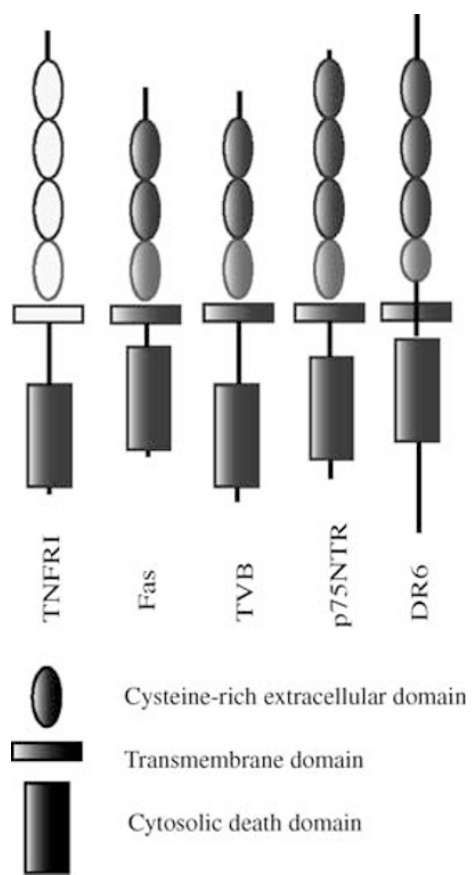

Figure 1 Representation of the major domains contained within the currently known Gallus gallus death receptors. The TNFRI extracellular and transmembrane domain architecture (unshaded) is predicted based upon the mouse and human TNFRI sequences

different members of this death receptor family. The answer will unquestionably prove to be complex, and will ultimately require a considerably greater understanding of the ligands that activate, and the cell signaling pathways activated by each individual receptor. The study of death receptor function will involve assessing several layers of complexity within each cell type. Specifically, it will be important to evaluate coexpression of decoy receptors, ${ }^{24}$ as well as decipher crosstalk with nondeath domaincontaining receptors. ${ }^{25}$ In addition, it will be critical to characterize the complement of intracellular adapter proteins (e.g. TRAFS), and to monitor proteolytic cleavage (e.g. TNF- $\alpha$-converting enzyme and matrix metalloproteinases) as well as post-translational processing (e.g. phosphorylation and glycosylation) of ligands and receptors to distinguish among signaling pathways mediated by death receptors. Evolution of death receptors has undoubtedly been influenced by these factors, as well as by their coevolution with both cognate ligands and nondeath receptor members of the TNFRSF. In spite of these complexities, examining the evolutionary context in which the death receptors have emerged within vertebrates can serve to establish a basis for understanding the divergence of individual functional specializations of each receptor. For instance, this evolutionary approach has previously provided evidence for both functional constraints and divergences among members of the caspase gene family. ${ }^{26,27}$ Moreover, from such insights we can offer predictions about the physiology of TNF death receptor family members in primary (untransformed) cells for which little, if any information is currently known. 


\section{The apparent emergence of death receptors in vertebrates}

Evolutionarily, the death receptors identified to date are unique to the vertebrate lineage. Among mammals, the TNFR superfamily encompasses at least eight death domaincontaining members, including Fas, TNFR1, p75NTR, ectodysplasin-A receptor (EDAR), death receptor (DR) 3, DR4, DR5, and $\mathrm{DR}^{28}$ (Table 1). Although previous studies have isolated several proteins containing death domains from invertebrates, there are no identifiable TNF receptor orthologs containing death domains found within the recently sequenced Drosophila genome ${ }^{29,30}$ and none yet isolated from Caenorhabditis elegans, or Porifera despite concerted efforts. ${ }^{31-33}$ Recent sequence information (including genomic, complementary DNA and EST) from a variety of nonmammalian species now provides the opportunity to examine evolutionary relationships within the death receptor family, and to speculate upon potential functional divergence or specialization among the members.

A search of all available databases for sequences with homology to the death domains from the eight human death receptors revealed representatives from various nonmammalian vertebrate species, including fish (Danio and Oryzias), frog (Xenopus and Silurana) and bird (Gallus) (Table 1). These non-mammalian vertebrate death domains were also used to search the database in order to identify death receptors from as many taxonomic lineages as available. A minimum BLAST similarity value of $E<0.01$ from our searches was used to identify putative death receptor homologs. Only one known adapter protein was identified using these criteria (Xenopus MyD88; $E=0.002$ compared to Xenopus fullback death domain ${ }^{34}$ ), and was not included in our analysis. Amino-acid sequences from putative death receptors were deduced from identified nucleic acid sequences, and regions predicted to encode the death domain were isolated prior to analysis (Figure 2, ClustalX alignment ${ }^{35}$ ). Across all species and death receptors, the death domain was bounded by two well-conserved blocks of amino acids and also contained an internal region characterized by several insertions and/or deletions and generally lower sequence conservation.

\section{Death receptors diverged early during vertebrate evolution}

The death receptor phylogeny (Figure 3 ) reveals a family of divergent proteins that predate the radiation of the vertebrates (estimated at 993-833 million years ago ${ }^{36,37}$ ). Each death receptor family member comprises a well-supported clade including representatives from the different classes of vertebrate taxa sampled. As a result, previously unidentified EST sequences (e.g. $\mathrm{Dr}$ BF717854=Fas; $\quad \mathrm{Gg}$ AW355430=TNFRI; $X e$ BI477064=TNFRI) as well as previously identified death receptors that remain unclassified (zebrafish hematopoietic death receptor, $\mathrm{Dr} \mathrm{ZH}-\mathrm{DR}$, and ovarian TNF receptor, DrOTR, within the DR5 clade) can be placed with certainty within established lineages (Figure 3).

Several observations and interesting patterns emerge from these phylogenetic data. For instance, remarkably different rates of divergence can be ascribed to individual members within the death receptor family. Some lineages are highly constrained, such as EDAR and DR6, both of which are remarkably conserved among animals as divergent as fish (EDAR, 87\% identity of DD compared to the human) and

Table 1 Vertebrate death receptors

\begin{tabular}{|c|c|c|c|c|c|c|c|c|}
\hline $\begin{array}{l}\text { Common name } \\
\text { used in the } \\
\text { analysis }\end{array}$ & $\begin{array}{l}\text { Standardized } \\
\text { family member } \\
\text { designations }\end{array}$ & $\begin{array}{l}\text { Human } \\
\text { Homo } \\
\text { sapiens }\end{array}$ & $\begin{array}{l}\text { Mouse } \\
\text { Mus } \\
\text { musculus }\end{array}$ & $\begin{array}{l}\text { Chicken } \\
\text { Gallus } \\
\text { gallus }\end{array}$ & $\begin{array}{l}\text { Frog } \\
\text { Xenopus } \\
\text { laevis }\end{array}$ & $\begin{array}{l}\text { Frog } \\
\text { Silurana } \\
\text { tropicalis }\end{array}$ & $\begin{array}{l}\text { Fish } \\
\text { Danio } \\
\text { rerio }\end{array}$ & $\begin{array}{l}\text { Fish } \\
\text { Oryzias } \\
\text { latipes }\end{array}$ \\
\hline $\begin{array}{l}\text { TNFRI } \\
\text { Fas } \\
\text { DR4 } \\
\text { DR5 } \\
\text { DR3 } \\
\text { p75NTR } \\
\text { DR6 } \\
\text { EDAR } \\
\text { TVB } \\
\text { Fullback (FB) } \\
\text { Death receptor } \\
\text { (ZH-DR) } \\
\text { OTR } \\
\text { Unknown-EST } \\
\text { Unknown-EST }\end{array}$ & $\begin{array}{l}\text { TNFRSF1A } \\
\text { TNFRSF6 } \\
\text { TNFRSF10A } \\
\text { TNFRSF10B } \\
\text { TNFRSF12 } \\
\text { TNFRSF16 } \\
\text { TNFRSF21 } \\
\text { Unclassified } \\
\text { Unclassified } \\
\text { Unclassified } \\
\text { Unclassified } \\
\text { Unclassified } \\
\text { Unnamed } \\
\text { Unnamed }\end{array}$ & $\begin{array}{l}\text { XP_006950 } \\
\text { M67454 } \\
4507558 \\
\text { AF012535 } \\
\text { NM_003790 } \\
\text { M14764 } \\
\text { NM_014452 } \\
\text { AF130988 }\end{array}$ & $\begin{array}{l}\text { NM_011609 } \\
\text { NM_007987 } \\
\text { NM_020275 } \\
\text { NM_033042 } \\
\text { NM_033217 } \\
\text { AF322069 } \\
\text { AF160502 }\end{array}$ & $\begin{array}{l}\text { AF296874 } \\
\text { P18519 } \\
\text { AF349908 } \\
\text { AF161712 }\end{array}$ & $\begin{array}{l}\text { AF172399 } \\
\text { AF131890 }\end{array}$ & BG512043 & $\begin{array}{l}\text { AF302789 } \\
\text { AF250042 } \\
\text { BF717834 } \\
\text { Al629342 }\end{array}$ & AF364814 \\
\hline
\end{tabular}

[TNFRI is also called CD120a, p55-R, TNFAR, TNFR60, TNF-r-I. Fas also known as CD95, APO-1, APT1. DR4 is Apo2, TRAIL-R1. DR5 is TRAIL-R2, KILLER, TRICK2A, TRICKB. DR3 is TRAMP, WSL-1, LARD, WSL-LR, DDR3, TR3, Apo-3. p75NTR is NGFR. DR6 is TR7. Standardized family member designations can be found at (http://www.gene.ucl.ac.uk/nomenclature/genefamily/tnftop.html). Death domain amino-acid sequences from each of the known human death receptors were isolated based upon the region corresponding to amino acids 370-438 of TNFRI. Corresponding amino-acid regions were used to search against the nr database and the EST databases with BLASTp and tBLASTn searches, respectively. Some of the sequences represent partial ESTs, and may not contain the entire predicted receptor coding region. Each of the sequences that were detected were subsequently used to search the protein database using BLASTx to verify that the most similar sequences to the unknown represented death receptors and not unrelated death domain-containing proteins] 
10

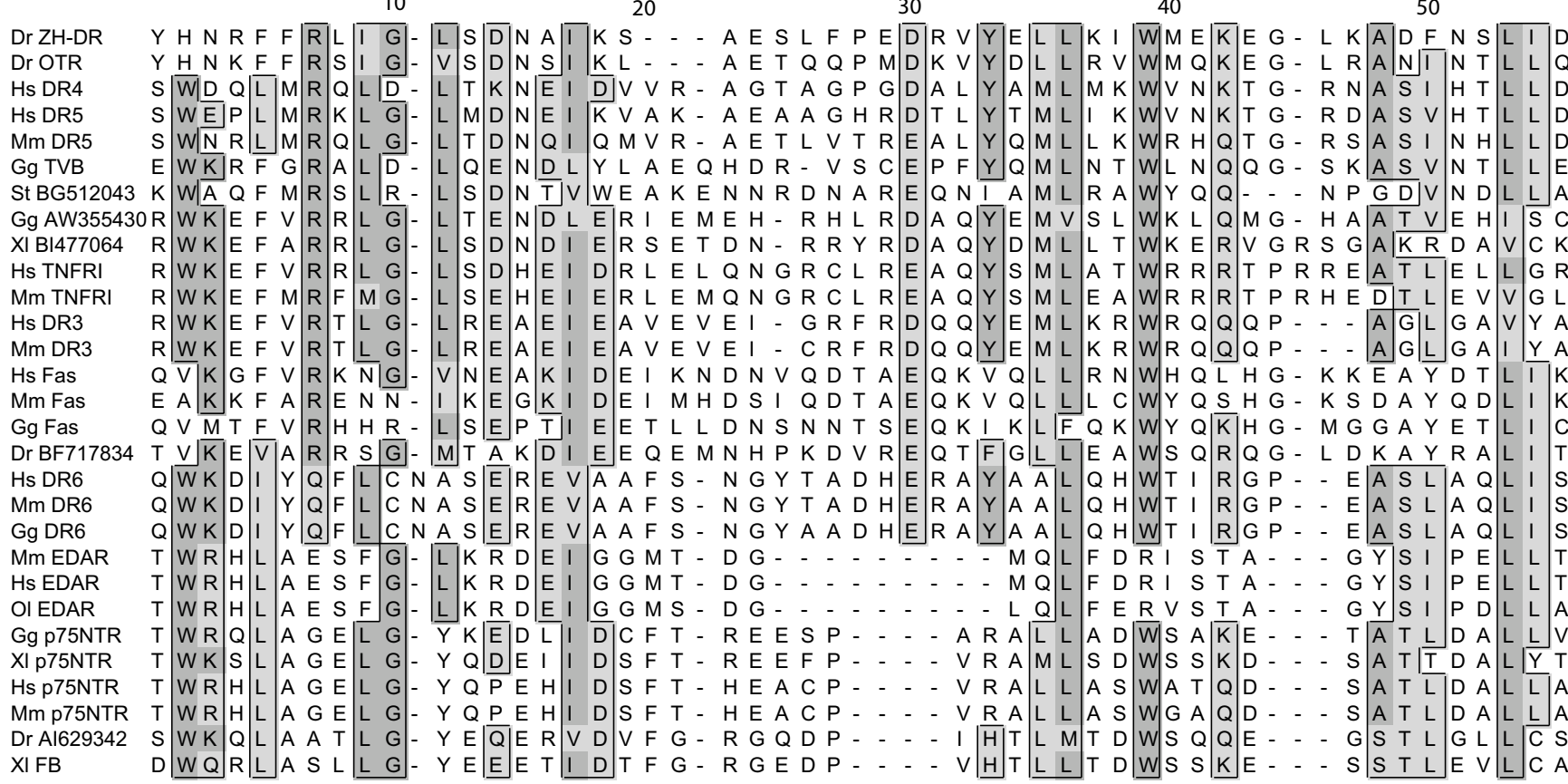

Figure 2 Alignment of the death domain of all sequences presented in Table 1 using the program Clustal X v. $1.81 .^{35}$ We used the Gonnet protein similarity matrix, ${ }^{58}$ a gap opening penalty of 10.00 and a gap extension penalty of 0.20 . The death domain refers to the region described in Table 1 . Dark and light gray boxes represent identical and similar amino acids, respectively. $\mathrm{Hs}=$ Homo sapiens, $\mathrm{Mm}=$ Mus musculus, $\mathrm{Gg}=\mathrm{Gallus}$ gallus, $\mathrm{XI}=\mathrm{Xenopus}$ laevis, $\mathrm{St}=\mathrm{Silurana}$ tropicalis, $\mathrm{Dr}=\mathrm{Daonio}$ rerio, $\mathrm{Ol}=$ Oryzias latipes

chickens (DR6, 98\% identity versus human). Clearly, we predict the existence of these receptors in other vertebrates, and accordingly expect to find conservation of critical functions that could illuminate these constraints on evolutionary divergence. Other family members demonstrate a high level of divergence in a fashion that largely recapitulates the splitting of the vertebrate lineage itself (e.g. Fas, see Figure 3). These observations enable us to predict that ligands that have coevolved with these receptors will show similar rates of divergence. This prediction currently holds true for the wellconserved mammalian EDAR ligand, ectodysplasin-A, and the highly divergent Fas ligand compared between human and mouse ( $94 \%$ identity compared to $75 \%$, respectively). Unfortunately, many of these ligands across species and even within mammals (e.g. DR6) have yet to be identified.

Additionally, in spite of the ancient divergence of the death receptor family, several members have continued to diversify within lineages, in particular, the related TRAIL receptors DR4 and DR5 in humans (there is currently no known ortholog of DR4 in the mouse). In humans, the origin of these receptors appears to be the result of a tandem duplication event, with both genes encoded on human chromosome 8 (DR4; 8p21, and DR5; 8p22-p21). Zebrafish also express a pair of closely related receptors, ZH-DR and OTR, most similar to the TRAIL receptors. Moreover, a third lineage containing two receptors within one species occurs in the p75NTR subgroup, with Xenopus expressing both p75NTR-like and a related receptor, fullback (FB; Genbank Accession AF131890), the function of which has not yet been described. The phylogeny of this p75NTR receptor clade predicts an older split within the vertebrate lineage, followed by the subsequent loss within mammalian species (human EST Genbank search with fullback revealed only the currently identified p75NTR). Resolution of this branch awaits identification of a more complete set of vertebrate sequences.

Finally, several interesting higher-order evolutionary relationships among the TNF death receptor family are clearly seen. These consist of well-supported groupings of receptor clades that are closely related to one another, in particular the TNFRI/DR3 receptors group together as do the EDAR/ p75NTR/DR6 receptors (Figure 3). The result is four distinct death receptor lineages, consistent with the observation that two rounds of genome duplication may have occurred around the time of the transition from invertebrates to vertebrates ${ }^{38}$ (Figure 3).

\section{Functional categories related to evolutionary subgroups}

We propose that the well-supported branches of the phylogeny fall into two major functional categories (Figure 3 , subgroups $a$ and $b$ ). The first group includes both the EDAR and p75NTR receptors that have been characterized as being involved in signaling pathways mediating development. EDAR is required for the development of epithelial appendages in vertebrates (hair and teeth in mice and scales in fish $^{39}$ ) and has recently been shown to interact with Edaradd, a death domain-containing adapter molecular similar to TRADD. ${ }^{40}$ Similarly, p75NTR is involved in mediating both survival and apoptosis during the development of neuronal cells. ${ }^{41}$ 


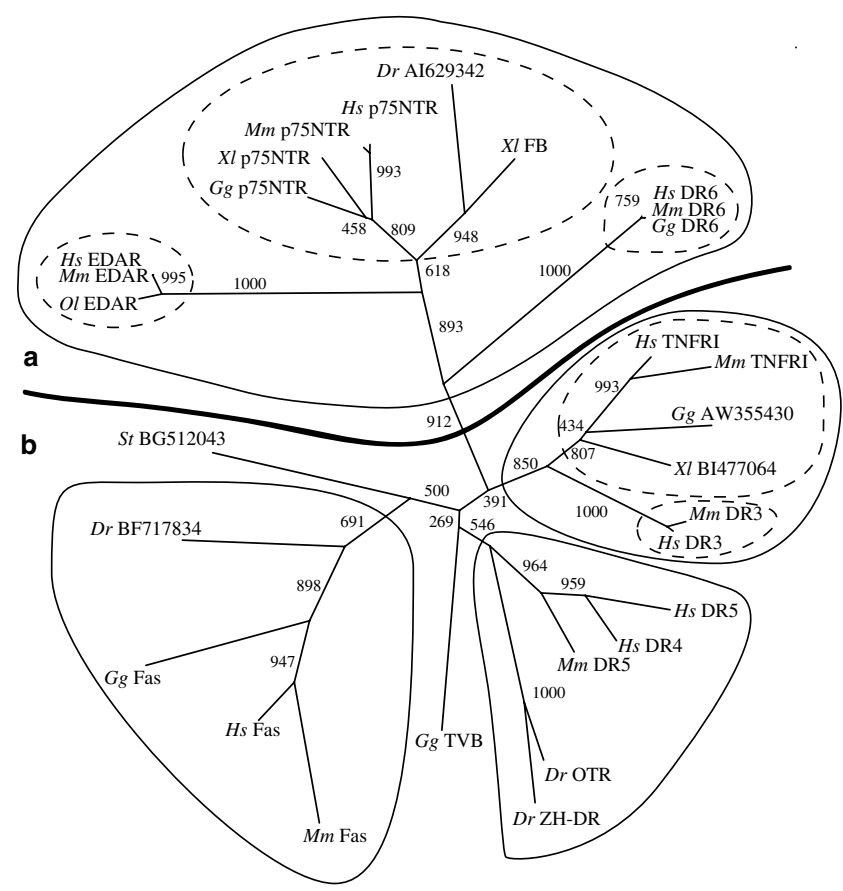

Figure 3 Phylogeny of the death receptor gene family based upon death domain homology. This tree was constructed using the neighbor-joining algorithm of the program NEIGHBOR in the PHYLIP (phylogeny inference package) program (Seattle, WA, USA). Distances were calculated using the Jones-TaylorThornton similarity matrix. ${ }^{59}$ Bootstrap support (out of 1000) is indicated. A full maximum likelihood tree (estimated using PROML from the PHYLIP package) estimated the same topology. In addition to the phylogeny shown, we searched for all death domains found in other nonreceptor proteins using the tBLASTn search. Including these death domains, found in both vertebrate and invertebrate species, in our analysis did not alter the topology or increase the resolution of the phylogeny for the receptor proteins, nor did they provide evidence a single ancestral death domain (data not shown). (a) and (b) denote different functional categories. All sequence accession numbers are found in Table 1 and abbreviations in the legend of Figure 2.

Phylogenetic analysis provides strong support for placing DR6 within this same major subgroup of developmentally specialized receptors, and it will be of special interest to elucidate the physiological role of this recently identified and highly conserved receptor. Surprisingly, DR6-deficient mice develop normally, and the only observed phenotypes are enhanced $\mathrm{CD}^{+}{ }^{+} \mathrm{T}$-cell proliferation and upregulated Th2 cytokine production. ${ }^{42}$ DR6 is capable of initiating apoptosis in select transformed cell lines, as well as activating NF- $\kappa \mathrm{B}$ and c-Jun terminal kinase in others. ${ }^{43}$ Accordingly, based on our phylogenetic classification, we predict that the physiological role of DR6 will be related to mediating developmental pathways, such as those that occur during T-cell differentiation. Moreover, given its widespread expression patterns, it is likely important in other tissue types as well. ${ }^{21,43}$

The second major functional category encompasses the remaining death receptors representing three separate clades, all of which play a role in mediating the immune response (Figure 3, subgroup b). Notably, the ancient divergence of these receptors occurs coincident with the emergence of the acquired immune response in vertebrate species. Within this category, TNFRI and DR3 form a single clade, suggesting a more recent divergence. DR3 is ex- pressed in tissues of immune system origin, specifically the spleen, thymus, and peripheral blood leukocytes with little or no expression in the other tissues examined. ${ }^{44}$ On the other hand, TNFRI has a more ubiquitous distribution, yet is still most often implicated in mediating the inflammatory response. ${ }^{45}$ These related receptors are also unique among the death receptors in that they can be phosphorylated on serine/threonine residues residing within the membrane proximal regions (not the death domains utilized to create this phylogeny) by the mitogen-activated protein kinase $\mathrm{p} 42$ (MAP/ERK). ${ }^{46}$

The Fas receptor forms another clade within this second functional category, and often has been linked to the control of cellular homeostasis within the immune system. ${ }^{47}$ Fas is expressed in a variety of normal cells, including ovarian granulosa cells, yet significantly the Fas ligand is reported to be limited to cells of immune system origin. ${ }^{47}$ This selective expression pattern facilitates a critical communication between the immune system and nonimmune cell types. Of particular interest was the finding that the phylogeny of Fas shows a surprisingly high degree of differentiation among vertebrates, including mammals. This result was unexpected given that Fas is most often depicted as having a comparatively direct signaling pathway linking receptor activation with caspase activity. ${ }^{48}$ The unexpectedly high rate of divergence among Fas receptors is consistent across the various vertebrates species, and continues within the mammalian lineage as demonstrated by only a $55 \%$ identity within the death domain of mouse Fas compared to human Fas. This lack of evolutionary constraint supports the proposal that Fas has a more diverse physiological role than was previously thought, including the potential to promote cell survival. ${ }^{47,49}$ Studies on the role of Fas in nonmammalian vertebrate species may shed additional light on this issue.

The remaining clade in this second functional category includes the human TRAIL receptors, DR4 and DR5 (Figure 3). Most research concerning TRAIL receptors has been directed towards the potential use of the ligand, TRAIL, as a chemotherapeutic agent, as carcinoma cell lines are often more susceptible to TRAIL-induced cell death than are primary cultures. ${ }^{50}$ Thus, although TRAIL receptors in mammals are reported to be expressed almost ubiquitously, ${ }^{51,52}$ the role of TRAIL receptors in non-cancerous cells has not yet been clearly establised. ${ }^{53}$ The widespread pattern of expression suggests that the function of TRAIL receptors is highly dependent upon cell-specifc regulatory mechanisms. Moreover, the existence of at least five receptors that bind the TRAIL ligand, including three receptors without death-inducing functions, accentuates the complexity involved in the regulation of this pathway. ${ }^{53}$ Within the TRAIL receptor clade (Figure 3, surrounding DR4 and DR5) are included two Danio receptors $\mathrm{ZH}-\mathrm{DR}$ and OTR, each with fairly limited tissue distributions. The death receptor, ZH-DR, is reported to be specific to haematopoietic cells, ${ }^{54}$ while OTR is expressed in a variety of tissues, but most strongly in the ovary. ${ }^{55}$ Based on our analysis we predict that ZH-DR and OTR represent duplicate genes that have evolved tissue-specific functions.

Inclusion of the chicken TVB within this clade is only very weakly supported, although the presence of a transmembrane domain and the similarity of $\mathrm{N}$-terminal cysteine-rich domains 
indicate that TVB is probably most closely related to human DR4 and 5. Interestingly, the chicken TVB receptor was originally isolated because of its ability to bind to envelope proteins of the cytopathic avian leukosis-sarcoma virus. ${ }^{56}$ Although viruses may interact with the TVB receptor to mediate infection, the identification of a naturally occurring (as yet unidentified) ligand is anticipated. Its role in viral immune response is especially fascinating in the light of our results showing the TVB death domain to be relatively divergent from all other death receptors. More recently, it was reported that the human DR5 receptor also mediates viral cytotoxicity in colonic epithelial cells; ${ }^{57}$ however, there is no evidence for direct binding of the receptor by viruses. Several of the death receptors have been implicated in mediating an immune response to viral infections, and no doubt this physiological function will be the subject of continuing research.

Finally, the Silurana (EST BG512043) sequence also appears within this functional category of death receptors involved in the immune response. The phylogeny places it closest to the Fas clade. The partial sequence from the EST database only contains information from the C-terminus through the death domain. In order to conclusively characterize this putative receptor, a more complete sequence identifying the presence of a transmembrane domain and a cysteine-rich region will be required. Such information, together with detailed studies of its expression and function, will help to elucidate why this death domain is so divergent from its neighbors.

\section{Conclusions}

The phylogenetic analysis presented herein indicates that members of the death receptor family represent an ancient divergence. Although ancient, several members of the death receptor family show strong phylogenetic relatedness to one another. Most interestingly, the evolution of death receptors has been quite dynamic, showing highly variable rates of constraint and divergence along the separate lineages and even showing continued differentiation through gene duplication within some vertebrate groups. Based on their phylogenetic relatedness, members of the death receptor family can be categorized into subgroups according to their predicted function. Significantly, our phylogenetic analysis demonstrates that the divergence of several death receptor clades involved in the immune response occurred concomitant with the initial appearance of adaptive immunity in vertebrates, while other clades appear to have become specialized in mediating development processes.

Finally, this review illuminates the critical need both for physiological studies in normal (non-transformed) cells to complement ongoing studies in transformed cell lines, as well as for additional comparative studies in non-mammalian vertebrates. Recall the model system discussed above in which hen granulosa cells express each of the five currently identified avian members of the death receptor family. We hypothesize that such receptors act in a highly pleiotropic fashion to mediate functions as diverse as communicating with the immune system, promoting differentiation, and signaling cell death. Moreover, we expect significant crosstalk among the death receptors such that activation of one receptor will rapidly modulate the expression and function of related family members. Ultimately, an understanding of such interactions will enable us to better understand the dynamics that contribute to the viability or death of developing ovarian follicles.

\section{Note Added in Proof}

Moreno et al. (2002) recently published the characterization of Eiger, a unique TNF homolog in Drosophila. Their results elegantly demonstrate that Eiger signals through the DRONC/ DARK pathway (homologous to caspase-9/Apaf-1 signaling in vertebrates) to initiate apoptosis, rather than through the death domain-dependent, adaptor-mediated activation of DREDD (homologous to caspase-8). This discovery suggests the evolutionarily important hypothesis that ancestral TNF receptors did not contain death domains. Accordingly, the death domain module may have been co-opted from the Tolllike receptor signaling pathway into the TNF receptor family linking these apoptosis initiating cytokines to multiple intracellular signaling pathways. These findings support our conclusion that death receptors are unique to the vertebrate lineage, and suggest a possible scenario in which TNF receptors became linked to death domain-mediated signaling pathways.

Moreno E, Yan M, and Basler K (2002) Evolution of TNF Signaling Mechanisms: JNK-Dependent Apoptosis Triggered by Eiger, the Drosophila Homolog of the TNF Superfamily. Curr. Biol. 12: 1263-1268.

\section{Acknowledgments}

This work has been supported by grants from the US Department of Agriculture (99-35203-7736) and the National Institutes of Health (HD36095) to ALJ.

\section{References}

1. Reed JC (2000) Mechanisms of apoptosis. AM. J. Pathol. 157: 1415-1430

2. Johnson AL and Bridgham JT (2002) Caspase-mediated apoptosis in the vertebrate ovary. Reproduction 124: 19-27

3. Nagata S and Goldstein P (1995) The Fas death factor. Science 267: 14491456

4. Nagata S (1997) Apoptosis by death factor. Cell 88: 355-365

5. Kramer PH (2000) CD95's deadly mission in the immune system. Nature 407: 789-795

6. Cottin V, Doan JES and Riches DWH (2002) Restricted localization of the TNF receptor CD120a to lipid rafts: a novel role for the death domain. J. Immunol. 168: 4095-4102

7. Baud V and Karin M (2001) Signal transduction by tumor necrosis factor and its relatives. Trends Cell. Biol. 11: 372-377

8. Aliprantis AO, Yang R-B, Weiss DS, Godowski P and Zychlinsky A (2000) The apoptotic signaling pathway activated by toll-like receptor-2. EMBO J. 19: 3325-3336

9. Chung JY, Park YC, Hong Y and Wu H (2002) All TRAFs are not created equal: common and distinct molecular mechanisms of TRAF-mediated signal transduction. J. Cell Sci. 115: 679-688

10. Schneider $P$ and Tschopp J (2000) Apoptosis induced by death receptors. Pharm. Acta. Helv. 74: 281-286

11. Naismith JH and Sprang SR (1998) Modularity in the TNF-receptor family. Trends Biochem. Sci. 23: 74-79 
12. Higgins DG (2000) Amino acid phylogeny and alignment. Adv. Protein Chem. 54: $99-135$

13. Tartaglia LA, Ayers TM, Wong GHW and Goeddel DV (1993) A novel domain within the 55kd TNF receptor signals cell death. Cell 74: 845-853

14. Hofmann K and Tschopp J (1995) The death domain motif found in Fas (Apo-1) and TNF receptor is present in proteins involved in apoptosis and axonal guidance. FEBS Lett. 371: 321-323

15. Telliez J-B, Xu G-Y, Woronicz JD, Hsu S, Wu J-L, Lin L, Sukits SF, Powers R and Lin L-L (2000) Mutational analysis and NMR studies of the death domain of the tumor necrosis factor receptor-1. J. Mol. Biol. 300: 1323-1333

16. McDonald III ER, Chui PC, Martelli PF, Dicker DT and El-Deiry WS (2001) Death domain mutagenesis of KILLER//DR5 reveals residues critical for apoptotic signaling. J. Biol. Chem. 276: 14939-14945

17. Itoh $N$ and Nagata S (1993) A novel protein domain required for apoptosis. J. Biol. Chem. 268: 10932-10937

18. Morita Y and Tilly JL (1999) Oocyte apoptosis: like sand through an hourglass. Dev Biol. 213: 1-17

19. Matikainen T, Perez Gl, Zheng TS, Kluzak TR, Rueda BR, Flavell RA and Tilly JL (2001) Caspase-3 gene knockout defines cell lineage specificity for programmed cell death signaling in the ovary. Endocrinology 142: 2468-2480

20. Johnson AL (2000) Granulosa cell apoptosis: conservation of cell signaling in an avian ovarian model system. Biol. Signals Recept. 9: 96-101

21. Bridgham JT, Bobe J, Goetz FW and Johnson AL (2001) Conservation of death receptor-6 in avian and piscine vertebrates. Biochem. Biophys. Res. Commun. 284: 1109-1115

22. Bridgham JT and Johnson AL (2001) Expression and regulation of Fas antigen and tumor necrosis factor receptor type I in hen granulosa cells. Biol. Reprod. 65: 733-739

23. Bridgham JT and Johnson AL (2002) Avian TVB (DR5-like) death receptor expression in hen ovarian follicles. Biochem. Biophys. Res. Commun. 291: 226-232

24. Ashkenazi A and Dixit VM (1999) Apoptosis control by death and decoy receptors. Curr. Opin. Cell Biol. 11: 255-260

25. Li X, Yang Y and Ashwell JD (2002) TNF-RII and c-IAP1 mediate ubiquitination and degradation of TRAF2. Nature 416: 345-349

26. Wang $Y$ and $G u X$ (2001) Functional divergence in the caspase gene family and altered functional constraints: statistical analysis and prediction. Genetics 158: $1311-1320$

27. Lamkanfi M, Declercq W, Kalai M, Saelens X and Vandenabeele P (2002) Alice in caspase land. A phylogenetic analysis of caspases from worm to man. Cell Death Differ. 9: 358-361

28. Locksley RM, Killeen N and Lenardo MJ (2001) The TNF and TNF receptor superfamilies: integrating mammalian biology. Cell 104: 487-501

29. Hu S and Yang $X(2000)$ dFADD, a novel death domain-containing adapter protein for the Drosophila caspase DREDD. J. Biol. Chem. 275: 30761-30764

30. Vernooy SY, Copeland J, Ghaboosi N, Griffin EE, Yoo SJ and Hay BA (2000) Cell death regulation in Drosophila: conservation of mechanism and unique insights. J. Cell Biol. 150: F69-F75

31. Ruvkin G and Hobert $O$ (1998) The taxonomy of developmental control in Caenorhabditis elegans. Science 282: 2033-2041

32. Muller WEG, Schroder HC, Skorokhod A, Bunz C, Muller IM and Grebenjuk VA (2001) Contribution of sponge genes to unravel the genome of the hypothetical ancestor of Metazoa (Urmetazoa). Gene 276: 161-173

33. Aravind L, Dixit VM and Koonin EV (2001) Apoptotic molecular machinery: vastly increased complexity in vertebrates revealed by genome comparisons. Science 291: 1279-1284

34. Prothmann C, Armstrong NJ and Rupp RA (2000) The Toll/L-1 receptor binding protein MyD88 is required for Xenopus axis formation. Mech. Dev 97: $85-92$

35. Thompson JD, Gibson TJ, Plewniak F, Jeanmougin F and Higgins DG (1997) The ClustalX windows interface: flexible strategies for multiple sequence alignment aided by quality analysis tools. Nucleic Acids Res. 24: 4876-4882

36. Wang DY-C, Kumar S and Hedges SB (1999) Divergence time estimates for the early history of animal phyla and the origin of plants, animals and fungi. Proc. R. Soc. Lond. B 266: 163-171
37. Nei M, Xu P and Glazko G (2001) Estimation of divergence times from multiprotein sequences for a few mammalian species and several distantly related organisms. Proc. Natl. Acad. Sci. 98: 2497-2502

38. Pennisi E (2001) Genome duplications: the stuff of evolution? Science 294: 2458-2460

39. Kondo S, Kuwahara Y, Kondo M, Naruse K, Mitani H, Wakamatsu Y, Ozato K, Asakawa S, Shimizu N and Shima A (2001) The medaka rs-3 locus required for scale development encodes ectodysplasin-A receptor. Curr. Biol. 11: 12021206

40. Headon DJ, Emmal SA, Ferguson BM, Tucker AS, Justice MJ, Sharpe PT, Zonana $J$ and Overbeek PA (2001) Gene defect in ectodermal dysplasia implicates a death domain adapter in development. Nature 414: 913-916

41. Miller FD and Kaplan DR (2001) Neurotrophin signaling pathways regulating neuronal apoptosis. Cell. Mol. Life Sci. 58: 1045-1053

42. Liu J, Na S, Glasebrook A, Fox N, Solenberg PJ, Zhang Q, Song HY and Yang $\mathrm{DD}$ (2001) Enhanced $\mathrm{CD} 4^{+} \mathrm{T}$ cell proliferation and Th2 cytokine production in DR6-deficient mice. Immunity 15: 23-34

43. Pan G, Bauer JH, Haridas V, Wang S, Liu D, Yu G, Vincenz C, Aggarwal BB, $\mathrm{Ni} J$ and Dixit VM (1998) Identification and functional characterization of DR6, a novel death domain-containing TNF receptor. FEBS Lett. 431: 351-356

44. Kitson J, Raven T, Jiang Y-P, Goeddel DV, Giles KM, Pun K-T, Grinham CJ, Brown R and Farrow SN (1996) A death-domain-containing receptor that mediates apoptosis. Nature 384 : $372-375$

45. Magor BG and Magor KE (2001) Evolution of effectors and receptors of innate immunity. Dev. Comp. Immunol. 25: 651-682.

46. Frankel SK, Van Linden AA and Riches DW (2001) Heterogeneity in the phosphorylation of human death receptors by p42 ${ }^{\text {mapk/erk2 }}$. Biochem. Biophys. Res. Commun. 288: 313-320

47. Sharma K, Wang RX, Zhang LY, Yin DL, Luo XY, Solomon JC, Jiang RF, Markos K, Davidson W, Scott DW and Shi YF (2000) Death the Fas way: regulation and pathophysiology of $\mathrm{CD} 95$ and its ligand. Pharmacol. Ther. 88: 333-347

48. Wallach D, Varfolomeev EE, Malinin NL, Goltsev YV, Kovalenko AV and Boldin MP (1999) Tumor necrosis factor receptor and Fas signaling mechanisms. Annu. Rev. Immunol. 17: 331-367

49. Budd RC (2002) Death receptors couple to both cell proliferation and apoptosis. J. Clin. Invest. 109: 437-442

50. Nagane M, Huang H-JS and Cavenee WK (2001) The potential of TRAIL for cancer chemotherapy. Apoptosis 6: 191-197

51. Walczak H, Degli-Esposti MA, Johnson RS, Smolak PJ, Waugh JY, Boiani N, Timour MS, Gerhart MJ, Schooley KA, Smith CA, Goodwin RG and Rauch CT (1997) TRAIL-R2: a novel apoptosis-mediating receptor for TRAIL. EMBO J. 16: $5386-5397$

52. Pan G, O'Rourke K, Chinnaiyan AM, Gentz R, Ebner R, Ni J and Dixit VM (1997) The receptor for the cytotoxic ligand TRAIL. Science 276: 111-113

53. Degli-Esposti M (1999) To die or not to die - the quest of the TRAIL receptors. J. Leukoc. Biol. 65: 535-542

54. Long Q, Haung H, Shafizadeh E, Liu N and Lin S (2000) Stimulation of erythropoiesis by inhibiting a new hematopoietic death receptor in transgenic zebrafish. Nat. Cell Biol. 2: 549-552

55. Bobe J and Goetz FW (2001) Molecular cloning and expression of TNF receptor and two TNF ligands in the fish ovary. Comp. Biochem. Physiol. B 129: 475-481

56. Brojatsch J, Naughton J, Rolls MM, Zingler K and Young JAT (1996) CAR1, a TNFR-related protein, is a cellular receptor for cytopathic avian leukosissarcoma viruses and mediates apoptosis. Cell 87: 845-855

57. Strater J, Walczak H, Pukrop T, Von Muller L, Hasel C, Kornmann M, Mertens T and Moller P (2002) TRAIL and its receptors in the colonic epithelium: a putative role in the defense of viral infections. Gastroenterology 122: 659-666

58. Gonnet GH, Cohen MA and Benner SA (1994) Analysis of amino acid substitution during divergent evolution: the 400 by 400 dipeptide substitution matrix. Biochem. Biophys. Res. Commun. 199: 489-496

59. Jones DT, Taylor WR and Thornton JM (1994) A mutation data matrix for transmembrane proteins. FEBS Lett. 339: 269-275 